\title{
Malnutrition and medical nutrition therapy in hospitalized children: a case study of using national malnutrition screening tools in northeastern Iran
}

\author{
Abbas Malek ${ }^{1}$, Maryam Hashemi ${ }^{2}$, Mehran Anjomrooz ${ }^{1}$, Parisa Torabi ${ }^{3}$, Bahareh Imani ${ }^{4}$
}

1. Dr Sheikh Hospital, Mashhad University of Medical Sciences, Mashhad, Iran.

2. Nutrition Department, Mashhad University of Medical Sciences, Mashhad, Iran.

3. Head of Clinical Nutrition Group. Nutrition Department, Ministry of Health and Medical Education. Iran.

4. Department of Pediatric, Mashhad University of Medical Sciences, Mashhad, Iran.

\section{Emails:}

-maleka2@mums.ac.ir, hashemim4@mums.ac.ir, anjomm881@mums.ac.ir, ptorabi2001@yahoo.com, imaniBH@ mums.ac.ir

\begin{abstract}
Background: Nationwide studies have focused only on prevalence of malnutrition in hospitalized children, while medical nutrition therapies and assessing nutritional interventions is neglected.

Methods: This research was conducted in tertiary level children hospitals in the NorthEastern region of Iran for 1 year from 2016 to 2017. Five questions were included in the initial assessment form and, if there was even one positive response, nutritional interventions were prescribed for the patients.

Results: A total of 65 children aged $\geq 5$ years and hospitalized for $\geq$ two days were included. 24.6\% of patients had $2>$ BMI Z-score $>-2$ at time of admission. At the beginning of the study, weight loss more than $10 \%$, and appetite loss or decreased food intake was observed in $10.8 \%$ and $20 \%$ of the study population, respectively. Median BMI percentile of patients with nutritional intervention was $8.9(0.1-98.7)$ at the beginning of the study and $12.7(0.1-98.4)$ at discharge time which shows a significant difference $(\mathrm{P}=0.01)$.

Conclusion: Medical nutrition therapy employed in this study prevented deterioration of nutritional status of children during hospitalization and was effective in stabilizing indices of nutritional status.
\end{abstract}

Keywords: Body mass index, hospitalized children, malnutrition.

DOI: https://dx.doi.org/10.4314/ahs.v19i1.31

Cite as: Malek A, Hashemi M, Anjomrooz M, Torabi P, B I. Malnutrition and medical nutrition therapy in hospitalized children: a case study of using national malnutrition screening tools in northeastern Iran. Afri Health Sci. 2019;19(1). 1566-1573. https://dx.doi.org/10.4314/ahs. v19i1.31

\section{Corresponding author:}

Bahareh Imani, Emam Reza Hospital

Mashhad University of Medical Sciences

P.O. Box 9188647189

Mashhad, Iran.

Tel: +989171118516

Fax: +985137277470

Email: imaniBH@mums.ac.ir

\section{Introduction}

The daily metabolism of children depends on receiving substrates such as food and vitamins ${ }^{1}$. While, inadequate intake of essential nutrients strongly affects children's growth $^{2}$, sick children especially who need to be hospitalized are likely to be affected by nutritional impairment ${ }^{3}$. The effect of malnutrition on the child cannot be limited only to the individual growth, it has been mentioned by various studies that there is an association between deterioration of the nutritional status upon admission or

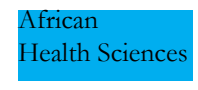

(C) 2019 Malek et al. Licensee African Health Sciences. This is an Open Access article distributed under the terms of the Creative commons Attribution License (https://creativecommons.org/licenses/BY/4.0), which permits unrestricted use, distribution, and reproduction in any medium, provided the original work is properly cited. 
during hospitalization with increased mortality, morbidity, prolonged length of hospital stay, and increased rates of complications such as infections ${ }^{1}$. The primary type of malnutrition that occurs due to inadequate food intake is most often seen in developing countries, and the second type occurs in developed countries that is associated with chronic diseases ${ }^{4}$.

According to scientific resources, the prevalence of malnutrition, particularly acute and/or chronic undernutrition among children admitted to the hospital remains considerable ${ }^{5}$. It has been stated that about $70-80 \%$ of children with malnutrition enter and leave the hospital, while their problem is not identified and treated ${ }^{6}$.

Hence, early identification of nutritional risk by screening nutritional status can be an important part of patients' standard care ${ }^{7}$. By early detection of children at risk for developing malnutrition, intervention and treatment can be started when is more effective and less expensive ${ }^{8}$. In spite of this fact, there is limited information on the malnourished children at time of admission, during hospitalization and at discharge time ${ }^{9}$, because, nutritional screening tools were designed to address adult patients and it is not too late that pediatric tools have been developed ${ }^{7}$. There are some known guidelines for nutrition screening developed by European Society for Clinical Nutrition and Metabolism (ESPEN), American Society for Parenteral and Enteral Nutrition (ASPEN), and European Society for Pediatric Gastroenterology, Hepatology and Nutrition (ESPGHAN) ${ }^{1}$.

Some of most famous tools to perform nutritional risk screening in children are Screening Tool for the Assessment of Malnutrition in Pediatrics (STAMP), Screening Tool for Risk On Nutritional status and Growth (Strongkids), and Pediatric Yorkhill Malnutrition Score (PYMS) that are developed by European countries, have not yet been completely examined in developing countries ${ }^{3}$. Moreover, there is not much information about application of nutritional screening tools in clinical practice and there is no consensus on which tools to use $\mathrm{e}^{8,10}$. A clinical nutritional assessment tool may be consisted of questions related to detailed medical and dietary history of the patient, measurements of body size and composition and laboratory data ${ }^{1}$. Depending on the criteria used to define malnutrition, various reports are available on the prevalence of malnutrition in different areas ${ }^{11}$. Weight-
for-Height score is the most frequently used criterion for acute malnutrition and body mass index (BMI) is also used to describe malnutrition ${ }^{12}$.

Despite the numerous studies globally published on the prevalence of malnutrition in children, evaluating the nutritional status of inpatient children is often neglected ${ }^{13}$. One of the most important reasons for this is the lack of identification of patients with or at risk of malnutrition in hospitals and as a result, lack of nutritional support in a timely and appropriate manner ${ }^{14-16}$. This problem has three main reasons: not routinely assess the nutritional status of children at the time of admission, inadequate number of pediatric clinical nutritionists and the complexity of using the usual methods for checking the nutritional status of children due to individual differences in the growth and maturity of children ${ }^{17,18}$.

The aim of this study was investigating nutritional status of inpatient children and evaluating effectiveness of medical nutrition therapy in children requiring nutritional support using nationally developed screening tools and anthropometric indices.

\section{Methods}

Children admitted to three tertiary university hospitals, Qaem, Imam Reza, and Dr. Sheykh, located in Mashhad, Iran, were enrolled in this cross-sectional interventional study between 20 March 2016 and 20 March 2017. Inclusion criteria were age between 5 and 18 year(s) and duration of hospitalization of at least 48 hours. Children admitted to units other than the pediatric wards or admitted to pediatric intensive care unit (PICU) and neonatal intensive care unit (NICU) and those with a specific diet like ketogenic diet were excluded.

\section{Nutritional status assessment forms}

In this study, children were evaluated at both admission and discharge times using primary and secondary forms. The form used to evaluate nutritional status of children at the time of admission is shown in appendix. This form was comprised of demographic information, anthropometrics, and 5 questions to determine the status of malnutrition. Patients at the time of discharge were also evaluated in terms of weight and BMI z-score. Positive response to each of the questions determining current nutritional status, weight loss, reduced intake and severe disease in the initial form filled for each patient indicated 
that the patient needs to receive medical nutrition therapy. Hence, professional nutrition assessment form was completed by dietitian (appendix).

\section{Medical nutrition therapy}

In medical nutrition therapy performed in this study at first, using guidelines of ESPEN and considering sex and age of patient, the patient's daily requirement to calorie intake, carbohydrate, fat, and protein was calculated by nutritionist. In the next step, the nutritionist documented medical nutrition therapies in the patient's records, which included the determination of the efficient feeding route (oral, enteral or parenteral), then the diet was verified by pediatric expert. Patient was provided with an appropriate oral, enteral (the standard hospital gavage solution composed of $0.45 \mathrm{Kcal} / \mathrm{ml}$ calories, $0.075 \mathrm{~g} / \mathrm{ml}$ protein, $0.17 \mathrm{~g} / \mathrm{ml}$ carbohydrates and $0.0417 \mathrm{~g} / \mathrm{ml}$ fat) or parenteral diet, dietary supplements in the form of syrup, pill, fortified calorie-dense powder or capsule if required. Moreover, patients' nurse was trained regarding enteral or parenteral diet and dietary supplements ordered for the patient and patient's attendant was trained regarding oral diet ordered for the patient.

After professional nutritional evaluating in the relevant format, in next visits of patients, nutritional status follow-up form was filled (appendix). The patient was followed-up according to this form in terms of changes in nutritional indices during hospitalization.

Finally, to evaluate nutritional status at time of discharge, the end part of follow up form having 5 questions was filled by responsible resident and criterion for judging the status was BMI Z-score less than -2 and greater than 2 .

\section{Ethical considerations}

The study was approved by the Ethical Committee of Mashhad University of Medical Sciences. Parents or legal attendants of the children were assured about the confidentiality of patient information and informed consent was obtained from them.

\section{Statistical analysis}

Statistical analysis was performed using SPSS version 23. To study and compare quantitative variables between the two groups, the distribution of each variable was first studied using the Kolmogorov-Smirnov test.With respect to the normal distribution of weight, BMI, and BMI z-score at admission and discharge, parametric paired t-test was used. While BMI percentiles at admission and discharge had not normal distribution and were assessed using non-parametric Wilcoxon test.

\section{Results}

In this study, 65 patients were enrolled, of which 28 $(43.1 \%)$ were female and $37(56.9 \%)$ were male. The mean age of the subjects was $112.4 \pm 35.84$ months. The lowest age of participants was 60 months and the highest was 192 months. The mean height of the participants was $130.27 \pm 18.43 \mathrm{~cm} .92 \mathrm{~cm}$ and $174 \mathrm{~cm}$ were respectively the smallest and the highest registered height of the patients. The average length of hospital stay was 7.09 \pm 5.7 days. The minimum length of hospital stay was 2 days and the maximum was 27 days. Based on the initial assessment checklist, the prevalence of acute malnutrition was $56.9 \%$ and 37 patients needed nutritional intervention. BMI Z-score of $24.6 \%(n=16)$ of patients was a sign of malnutrition. Moreover, $10.8 \%(n=7)$ of patients in the months leading up to the study had a weight loss of more than $10 \%, 20 \%(n=13)$ had anorexia or decreased food intake, and 44.6\% ( $n=29)$ had malignancy or chronic illness or were candidates for major surgery, all of which were indicative of malnutrition. 
Table 1. Demographic information and anthropometric indicators of patients who received nutrition therapy

\begin{tabular}{|c|c|c|c|c|c|c|c|}
\hline Samples & $\begin{array}{c}\text { AGE } \\
\text { (Month) }\end{array}$ & GENDER & $\begin{array}{c}\text { Pre-WEIGHT } \\
(\mathrm{kg})\end{array}$ & $\begin{array}{l}\text { Post-WEIGHT } \\
(\mathrm{kg})\end{array}$ & $\begin{array}{l}\text { HEIGHT } \\
\text { (CM) }\end{array}$ & $\begin{array}{l}\text { Pre-BMI } \\
\left(\mathrm{kg} \cdot \mathrm{m}^{-2}\right)\end{array}$ & $\begin{array}{c}\text { Post-BMI } \\
\left(\mathrm{kg} \cdot \mathrm{m}^{-2}\right)\end{array}$ \\
\hline 1 & 75 & $M$ & 25 & 24.5 & 110 & 20.7 & 20.2 \\
\hline 2 & 84 & $M$ & 20 & 20.2 & 112 & 15.9 & 16.1 \\
\hline 3 & 120 & $\mathrm{~F}$ & 34 & 34 & 142 & 16.9 & 16.9 \\
\hline 4 & 156 & $\mathrm{~F}$ & 55 & 55 & 135 & 30.2 & 30.2 \\
\hline 5 & 150 & $M$ & 35 & 35.5 & 151 & 15.4 & 15.6 \\
\hline 6 & 108 & $M$ & 21 & 22.5 & 125 & 13.4 & 14.4 \\
\hline 7 & 110 & $\mathrm{~F}$ & 17 & 18.5 & 125 & 10.9 & 11.8 \\
\hline 8 & 144 & $M$ & 42 & 42 & 140 & 21.4 & 21.4 \\
\hline 9 & 171 & $M$ & 28 & 28.5 & 132 & 16.1 & 16.4 \\
\hline 10 & 164 & $F$ & 34 & 35 & 152 & 14.7 & 15.1 \\
\hline 11 & 144 & $M$ & 32 & 32.3 & 150 & 14.2 & 14.4 \\
\hline 12 & 76 & $M$ & 16 & 17.5 & 103 & 15.1 & 16.5 \\
\hline 13 & 144 & $M$ & 31 & 31 & 150 & 13.8 & 13.8 \\
\hline 14 & 122 & $M$ & 25 & 25.5 & 140 & 12.8 & 13 \\
\hline 15 & 69 & $\mathrm{~F}$ & 16 & 16 & 114 & 12.3 & 12.3 \\
\hline 16 & 87 & $M$ & 20 & 21.2 & 132 & 11.5 & 12.2 \\
\hline 17 & 156 & $M$ & 58 & 58.5 & 174 & 19.2 & 19.3 \\
\hline 18 & 72 & $M$ & 16 & 17 & 107 & 14 & 14.8 \\
\hline 19 & 137 & $\mathrm{~F}$ & 34.5 & 35.5 & 150 & 15.3 & 15.8 \\
\hline 20 & 67 & $M$ & 17 & 17.3 & 106 & 15.1 & 15.4 \\
\hline 21 & 144 & $M$ & 28 & 24 & 146 & 13.1 & 11.3 \\
\hline 22 & 138 & $M$ & 37 & 37.5 & 145 & 17.6 & 17.8 \\
\hline 23 & 135 & $F$ & 38 & 38 & 144 & 18.3 & 18.3 \\
\hline 24 & 110 & $M$ & 29 & 29 & 129 & 17.4 & 17.4 \\
\hline 25 & 132 & $\mathrm{~F}$ & 38 & 38 & 140 & 19.4 & 19.4 \\
\hline 26 & 175 & $M$ & 71 & 71 & 164 & 26.4 & 26.4 \\
\hline 27 & 60 & $M$ & 12 & 13.5 & 94 & 13.6 & 15.3 \\
\hline 28 & 99 & $\mathrm{~F}$ & 26 & 26 & 111 & 21.1 & 21.1 \\
\hline 29 & 120 & $F$ & 22.5 & 22.5 & 130 & 13.3 & 13.3 \\
\hline 30 & 96 & $\mathrm{~F}$ & 27 & 27 & 124 & 17.6 & 17.6 \\
\hline 31 & 70 & $F$ & 20 & 20 & 120 & 13.9 & 13.9 \\
\hline 32 & 73 & $\mathrm{~F}$ & 13 & 13 & 98 & 13.5 & 13.5 \\
\hline 33 & 84 & $M$ & 18 & 18 & 118 & 12.9 & 12.9 \\
\hline 34 & 72 & $M$ & 9.8 & 9.8 & 92 & 11.6 & 11.6 \\
\hline 35 & 120 & $M$ & 18 & 18 & 116 & 13.4 & 13.4 \\
\hline 36 & 192 & $M$ & 58 & 54 & 163 & 21.8 & 20.3 \\
\hline 37 & 92 & $M$ & 17 & 17 & 116 & 12.6 & 12.6 \\
\hline
\end{tabular}

Data on demographic information and anthropometric indices of patients undergoing nutritional treatment are presented in Table 1.

Table 2 provides the same information for patients who did not need a nutritional intervention. Based on paired t-test, there was no significant difference in terms of the weight of patients receiving nutritional therapy between the time of admission and discharge $(\mathrm{P}=0.474)$. The difference was not also significant in the other group of pa- tients $(\mathrm{P}=0.060)$. In the patients with medical nutritional therapy, mean BMI at time of admission and discharge was $16.11 \pm 4.17$ and $16.26 \pm 4.05$, respectively $(\mathrm{P}=0.164)$. In the other group, mean BMI at time of admission and discharge was $16.06 \pm 2.59$ and $16.08 \pm 2.59$, respectively $(\mathrm{P}=0.103)$. Comparison of BMI between the time of admission and discharge based on the nutritional assessment forms indicates that there was no significant difference in this regard in both groups of study. 
Table 2. Demographic information and anthropometric indicators of patients who did not receive nutrition

\begin{tabular}{|c|c|c|c|c|c|c|c|}
\hline \multicolumn{8}{|c|}{ therapy } \\
\hline Samples & $\begin{array}{l}\text { AGE } \\
\text { (Month) }\end{array}$ & GENDER & $\begin{array}{c}\text { Pre-WEIGHT } \\
(\mathrm{kg})\end{array}$ & $\begin{array}{l}\text { Post-WEIGHT } \\
(\mathrm{kg})\end{array}$ & $\begin{array}{l}\text { HEIGHT } \\
\text { (CM) }\end{array}$ & $\begin{array}{l}\text { Pre-BMI } \\
\left(\mathrm{k}, \mathrm{m}^{2}\right)\end{array}$ & $\begin{array}{l}\text { Post-BMI } \\
\left(\mathrm{kg} \cdot \mathrm{m}^{2}\right)\end{array}$ \\
\hline 1 & 103 & $F$ & 23 & 23 & 130 & 13.6 & 13.6 \\
\hline 2 & 72 & $M$ & 18 & 18 & 115 & 13.6 & 13.6 \\
\hline 3 & 132 & $\mathrm{~F}$ & 28 & 28 & 135 & 15.4 & 15.4 \\
\hline 4 & 108 & $M$ & 35 & 35 & 129 & 21 & 21 \\
\hline 5 & 96 & $M$ & 25 & 25 & 130 & 14.8 & 14.8 \\
\hline 6 & 121 & $\mathrm{~F}$ & 34 & 34.3 & 152 & 14.7 & 14.8 \\
\hline 7 & 150 & $\mathrm{~F}$ & 52 & 52.3 & 155 & 21.6 & 21.8 \\
\hline 8 & 78 & $\mathrm{~F}$ & 20 & 20.5 & 119 & 14.1 & 14.5 \\
\hline 9 & 86 & $\mathrm{~F}$ & 17 & 17 & 107 & 14.8 & 14.8 \\
\hline 10 & 121 & $M$ & 25 & 25 & 140 & 12.8 & 12.8 \\
\hline 11 & 120 & $M$ & 25 & 25 & 119 & 17.7 & 17.7 \\
\hline 12 & 186 & $M$ & 50 & 50 & 155 & 20.8 & 20.8 \\
\hline 13 & 70 & $F$ & 17 & 17 & 115 & 12.9 & 12.9 \\
\hline 14 & 132 & $\mathrm{~F}$ & 31 & 31.2 & 147 & 14.3 & 14.4 \\
\hline 15 & 162 & $\mathrm{~F}$ & 44 & 44 & 150 & 19.6 & 19.6 \\
\hline 16 & 156 & $\mathrm{~F}$ & 38 & 38.2 & 154 & 16 & 16.1 \\
\hline 17 & 120 & $\mathrm{~F}$ & 30 & 30 & 135 & 16.5 & 16.5 \\
\hline 18 & 66 & $M$ & 20 & 20 & 112 & 15.9 & 15.9 \\
\hline 19 & 96 & $F$ & 25 & 25 & 120 & 17.4 & 17.4 \\
\hline 20 & 120 & $M$ & 34 & 34 & 135 & 18.7 & 18.7 \\
\hline 21 & 62 & $M$ & 15 & 14.8 & 103 & 14.1 & 14 \\
\hline 22 & 102 & $M$ & 34 & 34 & 147 & 15.7 & 15.7 \\
\hline 23 & 84 & $M$ & 22 & 22 & 118 & 15.8 & 15.8 \\
\hline 24 & 63 & $F$ & 18 & 18 & 118 & 12.9 & 12.9 \\
\hline 25 & 72 & $M$ & 20 & 20.1 & 116 & 14.9 & 14.9 \\
\hline 26 & 102 & $\mathrm{~F}$ & 28 & 28 & 144 & 13.5 & 13.5 \\
\hline 27 & 186 & $M$ & 33.5 & 33.5 & 140 & 17.1 & 17.1 \\
\hline 28 & 72 & $F$ & 32 & 32 & 128 & 19.5 & 19.5 \\
\hline
\end{tabular}

Based on the information obtained from the initial form of nutritional status assessment, BMI Z-score of $13(20 \%)$ patients on admission was less than -2 and 3 $(4.6 \%)$ patients had a BMI Z-score greater than 2. Based on the final form of nutritional status assessment, at time of discharge, $10(15.4 \%)$ patients had BMI Z-score $<-2$ and BMI Z-score was higher than 2 in $3(4.6 \%)$ patients. BMI Z-scores of patients at the beginning and end of the study in the intervention group are shown in Figure 1. 


\section{BMI Z-scores in patients with medical nutrition therapy}

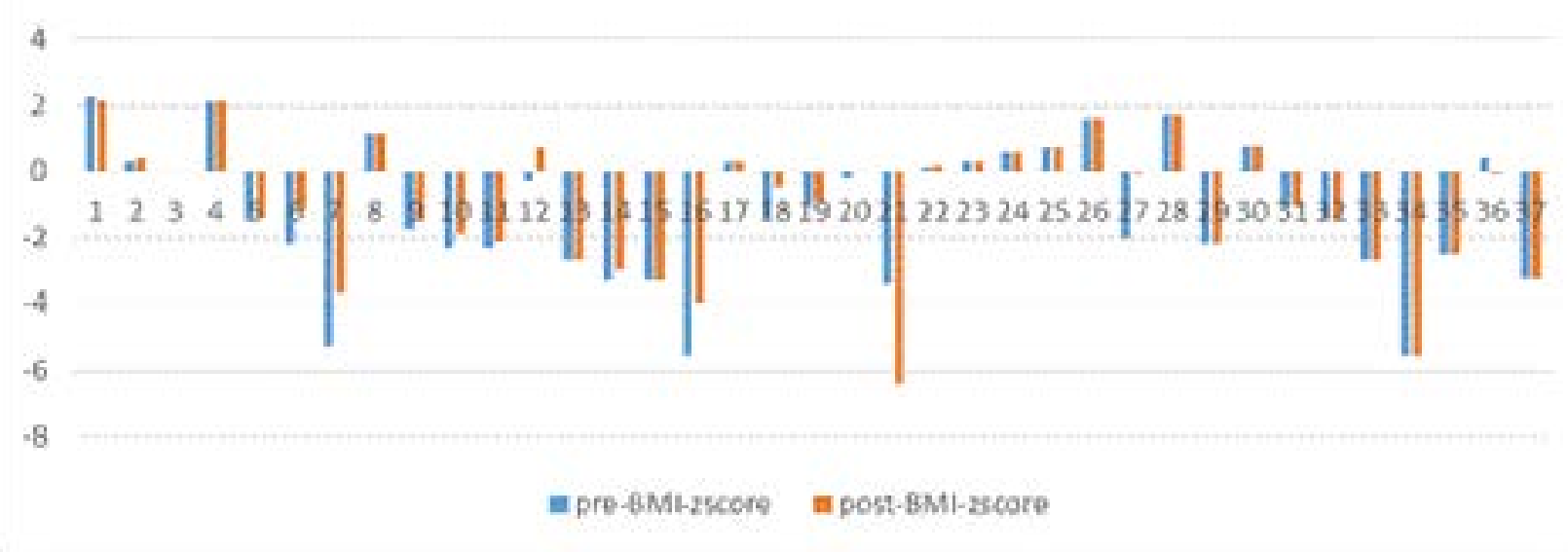

Fig.1. Comparison of BMI Z-scores of patients between the beginning and the end of the study in presence of medical nutrition therapy

Figure 2 shows similar information for patients who did not need nutritional treatment. Accordingly, in patients receiving nutritional support, mean BMI Z-score at time of admission and discharge was $-1.22 \pm 2.06$ and $-1.05 \pm 2.05$, respectively $(\mathrm{P}=0.182)$. While, mean $\mathrm{BMI}$
Z-score at time of admission and discharge in the other group was $-0.58 \pm 1.26$ and $-0.56 \pm 1.26$, respectively $(\mathrm{P}=0.234)$. Hence, there was no significant difference between initial and final BMI Z-scores in both groups.

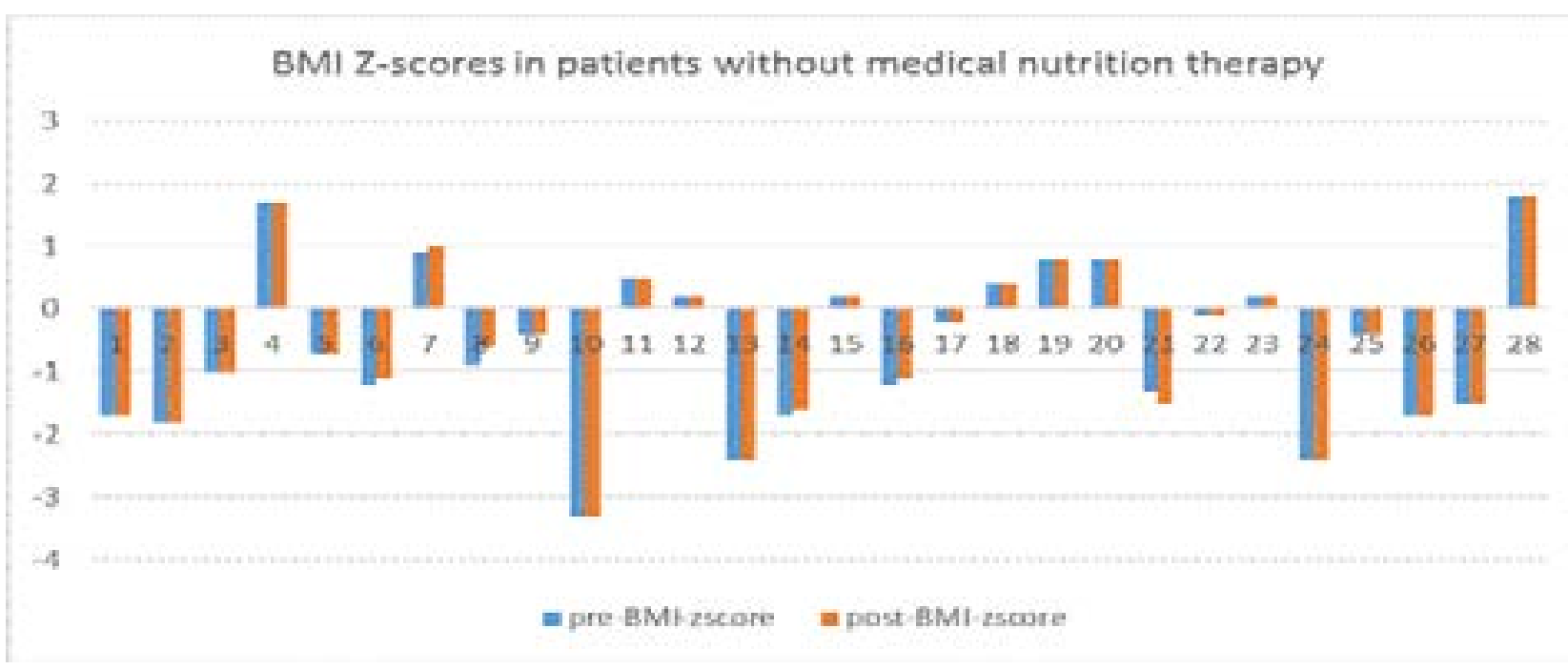

Fig.2. Comparison of BMI Z-scores of patients between the beginning and the end of the study without medical nutrition therapy 
Using Wilcoxon test, the median BMI percentile of patients who were selected for nutritional intervention was 8.9 (0.1-98.7) at the beginning of the study and eventually reached $12.7(0.1-98.4)$ at discharge time which shows a significant difference $(\mathrm{P}=0.01)$. But the difference of median BMI percentile between admission and discharge times was not considerable in the group of patients who did not receive additional nutritional support $(\mathrm{P}=0.249)$.

\section{Discussion}

In this study, the initial form of nutrition status assessment designed internally was used to screen hospitalized children with malnutrition. The validity and reliability of this screening tool was confirmed earlier by another study conducted at Taleghani Hospital of Tehran. The sensitivity of this tool which was defined as the percentage of people with malnutrition based on a dietitian's diagnosis had been obtained as $83.7 \%$. The specificity of this form that was defined as the percentage of people with good nutritional status based on a dietitian's diagnosis had been reported $84.6 \%{ }^{19}$.

In this study, the mean duration of hospital stay was 7.09 \pm 5.7 days. In the study conducted by Moeeni et al. ${ }^{3}$ length of hospital stay was directly affected by nutritional status and well-nourished patients of their study stayed on average $37 \%$ shorter than malnourished children and $33 \%$ of children with severe under-nutrition were hospitalized longer than 4 days. Although it has been stated that high nutritional risk status is associated with greater weight loss ${ }^{20}$, but no remarkable change in weight of patients occurred in this study.

$24.6 \%$ of the patients of current study had $2<\mathrm{BMI}$ Z-scores $<-2$, which is consistent with the findings of the study carried out in Italy by Campanozzi et al. ${ }^{21}$ which used same criterion and $21.9 \%$ of patients had BMI $\mathrm{Z}$-scores below the normal range distribution or above the upper limit. In the study of Moeeni et al. ${ }^{22}$ in New Zealand using STRONGkids nutritional risk screening tool, $24.7 \%$ of hospitalized children were malnourished. In total, using all criteria defined in the assessment form no. $1,56.9 \%$ of the patients of current study were diagnosed with malnutrition at time of admission. Tienboon $^{23}$ that studied nutrition problems of hospitalized children in Thailand, found that $50-60 \%$ of patients at ages 1-15 years were undernourished. These values are strongly higher than rates of malnutrition in developed countries. In the study of Joosten et al. ${ }^{9}$ in Netherlands, $19 \%$ of children were malnourished at admission. Malnutrition of admitted children was also reported to be $24.1 \%$ in Germany ${ }^{24}, 24.5 \%$ in Boston, $\mathrm{USA}^{25}$, and $7 \%$ in Glasgow, UK26. The differences of malnutrition rates among countries can be related to the various dietary patterns, measures selected to define malnutrition and approaches adopted to nutritional management ${ }^{2}$.

Some methodological limitations need clarification. We could not comprise all the potentially confounding factors. Next, the sample size was a limitation of this study that we cannot examine the sex-specific effects of variables.

\section{Conclusion}

This study showed that more than half of the hospitalized children suffered from malnutrition at time of admission. The nutritional status of children supported by medical nutrition therapies at the time of discharge, was similar to those of children who had not received additional nutritional support. Hence, medical nutrition therapy carried out in this research was effective in preventing from deterioration of nutritional status in malnourished children.

\section{Conflict of interest}

None.

\section{References}

1. Wonoputri N, Djais JT, Rosalina I. Validity of nutritional screening tools for hospitalized children. Journal of Nutrition and Metabolism. 2014;2014.

2. Mahdavi AM, Ostadrahimi A, Safaiyan A. Nutritional status of children hospitalized in Tabriz Paediatric Hospital, Islamic Republic of Iran, 2008. Eastern Mediterranean Health Journal. 2011; 17(1):36.

3. Moeeni V, Walls T, Day AS. Assessment of nutritional status and nutritional risk in hospitalized Iranian children. Acta Paediatrica. 2012; 101(10).

4. Mărginean O, Pitea AM, Voidăzan S, Mărginean C. Prevalence and assessment of malnutrition risk among hospitalized children in Romania. Journal of Health, Рориlation, and Nutrition. 2014; 32(1):97.

5. Sotoudeh M, Khalili M, Azizian M, Imani B. Pveralence of Malnutrition Based on Under Weight Inpatients in Pediatric Intensive Care Unit. IJPT. 2016;9(2):12333-40 
6. Sotoude M, Salehian T, Imani B, Kademi Gh, Comparison the Enteral Nutrition and Total Parenteral Nutrition Supports in the Course of Malnutrition Prevalence in Children Referring to Pediatric Hospital, Mashhad, Iran. The Social Sciences. 2016; 11(9): 2014-2017.

7. Chourdakis M, Hecht C, Gerasimidis K, Joosten KF, Karagiozoglou-Lampoudi T, Koetse HA,Ksiazyk J, Lazea C, Shamir R, Szajewska H, Koletzko B. Malnutrition risk in hospitalized children: use of 3 screening tools in a large European population-3. The American Journal of Clinical Nutrition. 2016; 103(5):1301-10.

8. Huysentruyt K, Alliet P, Muyshont L, Rossignol R, Devreker T, Bontems P, Dejonckheere J, Vandenplas Y, De Schepper J. The STRONGkids nutritional screening tool in hospitalized children: a validation study. Nutrition. 2013; 29(11):1356-61.

9. Joosten KF, Zwart H, Hop WC, Hulst JM. National malnutrition screening days in hospitalised children in The Netherlands. Archives of Disease in Childhood. 2010; 95(2):141-5.

10. Durakbaşa ÇU, Fettahoğlu S, Bayar A, Mutus M, Okur H. The prevalence of malnutrition and effectiveness of STRONGkids tool in the identification of malnutrition risks among pediatric surgical patients. Balkan Medical Journal. 2014;31(4):313.

11. Spagnuolo MI, Liguoro I, Chiatto F, Mambretti D, Guarino A. Application of a score system to evaluate the risk of malnutrition in a multiple hospital setting. ItalianJournal of Pediatrics. 2013;39(1):81.

12. Joosten KF, Hulst JM. Malnutrition in pediatric hospital patients: current issues. Nutrition. 2011;27(2):133-7. 13. Rocha F. C, Garcia R, Freitas A. W. de P, Souza A. L. de, Valadares Filho S. de C, Pereira O. G, Rigueira J. P. S, Tonucci R. G, Rocha G. C. Intake and digestibility of lactating dairy cows fed diets containing coffee hulls. Rev Bras Zootec; 2006; 35 (5): 2154-2162

14. Beheshti M, Imanzadeh F, shahidi N. Evaluation of nutritional status in children admitted to the neurology ward of Mofid Children Hospital. Iran J Child Neurology. 2010; 3(4): 51-58

15. Marteletti O, Caldari D, Guimber D, Mention K, Michaud L, Gottrand F. Malnutrition screening in hospital- ized children: influence of the hospital unit on its management. Arch Pediatr. 2005; 12(8):1226-311.

16. Oztürk Y, Büyükgebiz B, Arslan N, Ellidokuz H.Effects of hospital stay on nutritional anthropometric data in Turkish children. J Trop Pediatr. 2003; 49(3):189-90.

17. Bosy-Westphal A1, Danielzik S, Dörhöfer RP, Later W, Wiese S, Müller MJ. Phase angle from bioelectrical impedance analysis: population reference values by age, sex, and body mass index. JPEN J Parenter Enteral Nutr. 2006; 30(4):309-16.

18. Nagano M1, Suita S, Yamanouchi T. The validity of bioelectrical impedance phase angle for nutritional assessment in children. J Pediatr Surg. 2000; 35(7):1035-9

19. Mirmiran P, Hoseinpoor Niazi S, Hamayeli Mehrbani H, Kavian F, Azizi F. Assessing validity and reliability of patients' malnutrition screening tool at time of admission to hospital. Iranian Journal of Nutrition and Food Technology. 2008; 4(1):39-47.

20. Cao J, Peng L, Li R, Chen Y, Li X, Mo B, Li X. Nutritional risk screening and its clinical significance in hospitalized children. Clinical nutrition. 2014 Jun 1;33(3):432-6.

21. Campanozzi A, Russo M, Catucci A, Rutigliano I, Canestrino G, Giardino I, Romondia A, Pettoello-Mantovani M. Hospital-acquired malnutrition in children with mild clinical conditions. Nutrition. 2009;25(5):540-7.

22. Moeeni V, Walls T, Day AS. The STRONGkids nutritional risk screening tool can be used by paediatric nurses to identify hospitalised children at risk. Acta Paediatrica. 2014;103(12).

23. Tienboon P. Nutrition problems of hospitalized children in a developing country: Thailand. Asia Pac J Clin Nutr. 2002; 11:258-62. PubMed.

24. Imani B, Hosseini Nasab M, Gholampour Z, Abdollahpour N, Mehrbakhsh Z. Assessment of Malnutrition Based on Three Nutritional Risk Scores in Hospitalized iranian childeren. Pediatrics. 2015 Feb;135(1):15-16

25. Gholampour Z, Hosseininasab M, Khademi GH, Sezavar M, Abdollahpour N, , Imani B. Assessment of Nutritional Status Based on STRONGkids Tool in Iranian Hospitalized Children. International Journal of Child Health and Nutrition. 2015 Aug; 4 (1): 61-66

26. Hendrikse WH, Reilly JJ, Weaver LT. Malnutrition in a children's hospital. Clinical Nutrition, 1997; 16:13-18. 